\title{
Lysobacter korlensis sp. nov. and Lysobacter bugurensis sp. nov., isolated from soil
} Correspondence
Cheng-Xiang Fang
cxfang@whu.edu.cn

\author{
Lei Zhang, ${ }^{1,2}$ Juan Bai, ${ }^{1}$ Yang Wang, ${ }^{2}$ Gao-Lin Wu, ${ }^{3}$ Jun Dai ${ }^{2}$ \\ and Cheng-Xiang Fang ${ }^{2}$
}

\author{
${ }^{1}$ College of Life Sciences, Northwest A\&F University, Yangling, Shaanxi 712100, PR China \\ ${ }^{2}$ College of Life Sciences, Wuhan University, Wuhan 430072, PR China \\ ${ }^{3}$ State Key Laboratory of Soil Erosion and Dryland Farming on the Loess Plateau, Northwest A\&F \\ University, Institute of Soil and Water Conservation, CAS \& MWR, Yangling, Shaanxi 712100, PR \\ China
}

Two Gram-reaction-negative, rod-shaped, gliding, yellow-pigmented bacterial strains, designated ZLD-17 $7^{\top}$ and ZLD-29 ${ }^{\top}$, were isolated from arid soil samples collected from Xinjiang Province, north-west China, and subjected to analysis using a polyphasic taxonomic approach. Both novel strains required $1.0-2.0 \%(w / v)$ sea salts for optimal growth. Phylogenetic analysis based on 16S rRNA gene sequences indicated that these two strains belong to the genus Lysobacter within the class Gammaproteobacteria. Strain ZLD-17 ${ }^{\top}$ showed highest $16 \mathrm{~S}$ rRNA gene sequence similarities to Lysobacter capsici KCTC $22007^{\top}$ (96.9\%), Lysobacter spongiïcola DSM $21749^{\top}(96.8 \%)$ and Lysobacter koreensis KCTC $12204^{\top}(96.8 \%)$, whereas strain ZLD-29 ${ }^{\top}$ showed highest sequence similarities to Lysobacter niastensis DSM $18481^{\top}(96.0 \%)$ and Lysobacter enzymogenes DSM 2043 ${ }^{\top}$ (95.9\%). 16S rRNA gene sequence similarity between ZLD-17 $7^{\top}$ and ZLD-29 ${ }^{\top}$ was $96.1 \%$. The DNA G +C contents of strains ZLD-17 $7^{\top}$ and ZLD-29 ${ }^{\top}$ were 67.9 and $68.2 \mathrm{~mol} \%$, respectively. The major cellular fatty acids of both strains were summed feature 3 (iso- $\mathrm{C}_{15: 0} 2-\mathrm{OH}$ and/or $\mathrm{C}_{16: 1} \omega 7 c$ ), iso- $\mathrm{C}_{17: 1} \omega 9 c$, iso- $\mathrm{C}_{16: 0}, \mathrm{C}_{16: 0}$ and iso- $\mathrm{C}_{11: 0} 3-\mathrm{OH}$; their predominant isoprenoid quinone was $\mathrm{Q}-8$ and their major polar lipids were diphosphatidylglycerol, phosphatidylethanolamine and phosphatidylglycerol. Based on their phenotypic characteristics, phylogenetic position as determined by $16 \mathrm{~S}$ rRNA gene sequence analysis and chemotaxonomic data, strains ZLD-17 ${ }^{\top}$ (=CCTCC AB $207174^{\top}=$ KCTC $23076^{\top}$ ) and ZLD-29 $9^{\top}$ (=CCTCC AB $207175^{\top}=$ KCTC $23077^{\top}$ ) represent two novel species of the genus Lysobacter, for which the names Lysobacter korlensis sp. nov. and Lysobacter bugurensis sp. nov. are proposed, respectively.
The genus Lysobacter was first described by Christensen \& Cook (1978) and the description was emended by Park et al. (2008). Members of the genus Lysobacter, in the family Xanthomonadaceae, contain ubiquinone Q-8 as the major respiratory quinone and have a high DNA G +C content (Park et al., 2008; Wang et al., 2009). Members of the genus are strongly proteolytic and characteristically lyse a variety of micro-organisms, including Gram-negative bacteria, Gram-positive bacteria, cyanobacteria, filamentous fungi, yeasts, algae and nematodes (Christensen \& Cook, 1978). At the time of writing, the genus comprised

Abbreviation: PNPG, $p$-nitrophenyl- $\beta$-D-galactopyranoside.

The GenBank/EMBL/DDBJ accession numbers for the 16S rRNA gene sequences of strains ZLD-17 ${ }^{\top}$ and ZLD-29 ${ }^{\top}$ are EU908051 and EU780693, respectively.

Two supplementary figures are available with the online version of this paper.
17 species with validly published names, including the recently described species Lysobacter soli (Srinivasan et al., 2010) and Lysobacter panaciterrae (Ten et al., 2009). During the course of an investigation of the culturable bacterial community in soil from an arid area in Xinjiang Province, north-west China, 180 bacterial strains were isolated; 60 pure cultures were randomly selected for 16S rRNA gene sequencing and phylogenetic analysis. These isolates included members of the phyla Actinobacteria, Firmicutes, Proteobacteria, Bacteroidetes and Deinococcus-Thermus. In this study, a polyphasic taxonomic approach was used to characterize two isolates, designated strains ZLD-17 ${ }^{\mathrm{T}}$ and ZLD-29 ${ }^{\mathrm{T}}$, belonging to the Gammaproteobacteria. On the basis of phenotypic characteristics, chemotaxonomic data and phylogenetic analysis of $16 \mathrm{~S}$ rRNA gene sequences, the two isolates were found to represent two novel species of the genus Lysobacter.

Strains ZLD- $17^{\mathrm{T}}$ and ZLD-29 ${ }^{\mathrm{T}}$ were isolated from soil taken from an arid area $\left(42^{\circ} 78^{\prime}-43^{\circ} 15^{\prime} \mathrm{N} 88^{\circ} 65^{\prime}-88^{\circ} 83^{\prime} \mathrm{E}\right)$ 
in Xinjiang Province, north-west China. Soil samples were suspended in sterilized water and diluted solutions were spread on agar plates containing half-strength marine broth 2216 (MB; Difco) supplemented with 1.5\% agar. Isolation was achieved after incubation at $28{ }^{\circ} \mathrm{C}$ for 1 week. Unlike other Lysobacter species with validly published names, strains ZLD-17 $7^{\mathrm{T}}$ and ZLD-29 ${ }^{\mathrm{T}}$ showed poor growth on R2A agar (Difco); the former did not grow and the latter formed several small colonies after incubation at $28{ }^{\circ} \mathrm{C}$ for 1 week. Thus, the isolates were routinely cultivated on halfstrength $\mathrm{MB}$ agar at $28{ }^{\circ} \mathrm{C}$ and stored as glycerol suspensions $(20 \%, v / v)$ at $-80{ }^{\circ} \mathrm{C}$.

For $16 \mathrm{~S}$ rRNA gene sequencing and phylogenetic analysis, DNA was extracted using a commercial genomic DNA extraction kit (ChaoShi-Bio). The primer pair 27f (5'-GAGTTTGATCCTGGCTCAG-3') and 1527r (5'-AGAAAGGAGGTGATCCAGCC-3') was used for amplification of the 16S rRNA gene (Lane, 1991). PCR and 16S rRNA gene sequencing were carried out as described by Lin et al. (2004). Identification of phylogenetic neighbours and calculation of pairwise $16 \mathrm{~S}$ rRNA gene sequence similarities were achieved using the EzTaxon server (http://www. eztaxon.org/; Chun et al., 2007). Phylogenetic analysis was performed by using MEGA version 4.1 (Tamura et al., 2007), after multiple alignment of the data via CLUSTAL_X (Thompson et al., 1997). A distance matrix method (distance options according to the Kimura two-parameter model), including clustering by using the neighbour-joining method, and a discrete character-based maximumparsimony method were used. In each case, bootstrap values were calculated based on 1000 replications.

The almost complete 16S rRNA gene sequences for strains ZLD-17 ${ }^{\mathrm{T}}$ and ZLD-29 ${ }^{\mathrm{T}}$ (1448 and $1453 \mathrm{bp}$, respectively) were determined. The $16 \mathrm{~S}$ rRNA gene sequence similarity between strains ZLD- $17^{\mathrm{T}}$ and ZLD-29 $9^{\mathrm{T}}$ was $96.1 \%$. In phylogenetic trees based on neighbour-joining and maximum-parsimony algorithms (Fig. 1; Supplementary Fig. S1, available in IJSEM Online), strains $Z L D-17^{\mathrm{T}}$ and $\mathrm{ZLD}-29^{\mathrm{T}}$ fell within the radiation of the cluster comprising species of the genus Lysobacter. However, the topology of the phylogenetic tree generated using the maximum-parsimony algorithm (Supplementary Fig. S1) differed somewhat from that of the tree reconstructed using the neighbour-joining method (Fig. 1). Strain $\mathrm{ZLD}-17^{\mathrm{T}}$ formed a clade with Lysobacter koreensis $\mathrm{KCTC} 12204^{\mathrm{T}}$ in the neighbour-joining tree but formed a distinct monophyletic group in the maximumparsimony tree. Strain ZLD-29 ${ }^{\mathrm{T}}$ formed a clade with Lysobacter xinjiangensis RCML- $52^{\mathrm{T}}$ in both phylogenetic trees. Strain ZLD-17 ${ }^{\mathrm{T}}$ exhibited highest $16 \mathrm{~S}$ rRNA gene sequence similarities to Lysobacter capsici KCTC $22007^{\mathrm{T}}$ (96.9\%), Lysobacter spongiicola DSM $21749^{\mathrm{T}}(96.8 \%)$ and L. koreensis KCTC $12204^{\mathrm{T}}(96.8 \%)$, whereas strain ZLD-29 ${ }^{\mathrm{T}}$ showed highest sequence similarities to Lysobacter niastensis DSM $18481^{\mathrm{T}}(96.0 \%)$ and Lysobacter enzymogenes DSM $2043^{\mathrm{T}}(95.9 \%)$. The low levels of $16 \mathrm{~S}$ rRNA gene sequence similarity $(<97 \%)$ among Lysobacter species with validly published names and the novel isolates indicated that the two isolates represented two novel genomic species of the genus Lysobacter (Stackebrandt \& Goebel, 1994).

For strains ZLD-17 ${ }^{\mathrm{T}}$ and ZLD-29 ${ }^{\mathrm{T}}$, cellular morphology was determined by using phase-contrast microscopy and transmission electron microscopy with 2-day-old cells grown on half-strength MB agar. The Gram reaction was carried out according to the classical Gram procedure described by Doetsch (1981). Gliding motility was determined as described by Bowman (2000). Growth was assessed on half-strength $\mathrm{MB}$ medium at $4,7,10,15,20$, $28,33,37,42$ and $45{ }^{\circ} \mathrm{C}$ and at $\mathrm{pH} 4-11$ at intervals of one $\mathrm{pH}$ unit to determine the temperature and $\mathrm{pH}$ ranges for

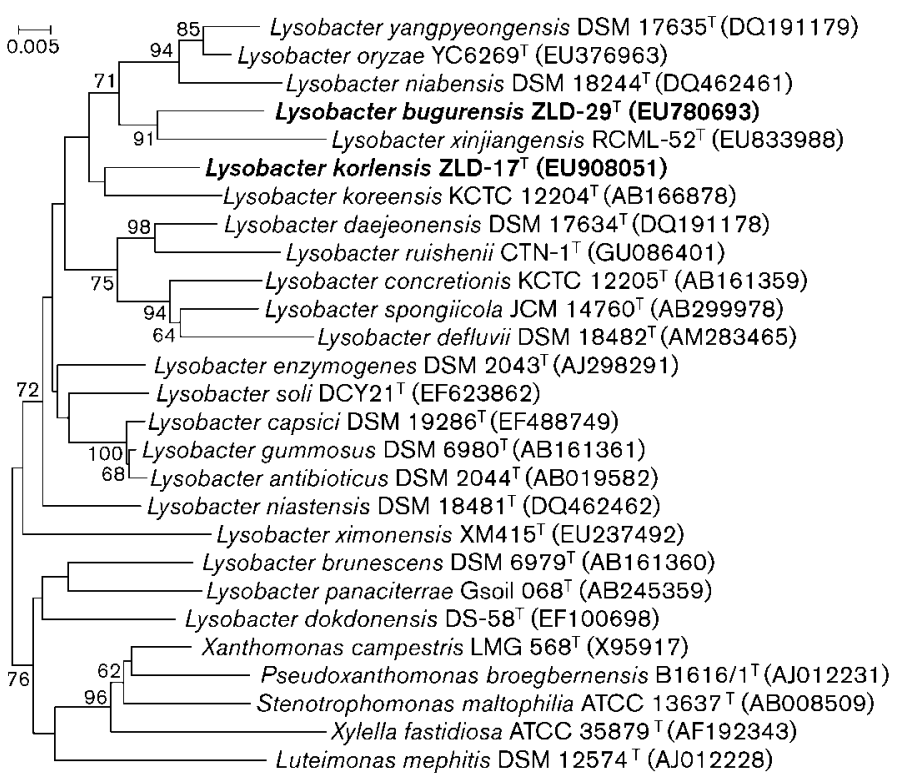

Fig. 1. Neighbour-joining phylogenetic tree based on 16S rRNA gene sequences showing the positions of strains ZLD-17 ${ }^{\top}$ and ZLD-29 ${ }^{\top}$ and closely related species. Bootstrap values $>50 \%$ (based on 1000 replications) are shown at branching points. Bar, 0.005 substitutions per nucleotide position. 
growth. Growth in the absence of $\mathrm{NaCl}$ and in the presence of $0.5-5.0 \%(\mathrm{w} / \mathrm{v}) \mathrm{NaCl}$ (in increments of $0.5 \%$ ) was investigated in peptone-yeast extract (PY) medium (Bacto peptone, $2.5 \mathrm{~g}$; yeast extract, $0.5 \mathrm{~g}$; distilled water, $1 \mathrm{l}$ ). Growth was also determined in PY medium containing 0$5 \%(\mathrm{w} / \mathrm{v})$ sea salts (increments of $0.5 \%$; Sigma). Growth under anaerobic conditions was determined by incubation for 1 week in an anaerobic chamber (Oxoid AnaeroJar System) on half-strength $\mathrm{MB}$ agar. Oxidase activity was tested using a $1 \%$ solution of tetramethyl- $p$-phenylenediamine (Kovács, 1956). Catalase activity was detected by assessing the production of bubbles after the addition of a drop of $3 \% \mathrm{H}_{2} \mathrm{O}_{2}$. Tests to determine decomposition of adenine, guanine, hypoxanthine, xanthine, tyrosine, elastin, keratin and testosterone were performed using the method of Gordon \& Smith (1955). Hydrolysis of starch and casein was tested as described by Smibert \& Krieg (1994). Hydrolysis of hippurate was determined as described by Kinyon \& Harris (1979). Haemolytic activity was tested on half-strength $\mathrm{MB}$ agar supplemented with $5 \%(\mathrm{v} / \mathrm{v})$ defibrinated sheep blood. Hydrolysis of CM-cellulose $(0.1 \%, \mathrm{w} / \mathrm{v})$ and chitin from crab shells $(1 \%, \mathrm{w} / \mathrm{v})$ was also tested. Growth was evaluated on trypticase soy agar (TSA; Difco), MacConkey agar (Difco) and brain-heart infusion (BHI) agar (Becton Dickinson) at $28{ }^{\circ} \mathrm{C}$. Acid production from carbohydrates was determined as described by Leifson (1963). The commercially available API 20 E, API 20 NE, API ID 32GN and API ZYM systems (bioMérieux) were used to determine biochemical properties, utilization of carbohydrates and enzyme activities according to the manufacturer's instructions except that all suspension media for strains ZLD- $17^{\mathrm{T}}$ and ZLD-29 $9^{\mathrm{T}}$ were supplemented with $1 \%(\mathrm{w} / \mathrm{v})$ sea salts.

Cells of strains ZLD- $17^{\mathrm{T}}$ and ZLD- $29^{\mathrm{T}}$ were aerobic, Gramreaction-negative, gliding and rod-shaped (Supplementary Fig. S2). Colonies of both strains were yellow, circular and convex with clear margins after incubation at $28{ }^{\circ} \mathrm{C}$ for 2 days on half-strength $\mathrm{MB}$ agar (Difco). Sea salts were favourable for growth of both novel strains. Strain ZLD$17^{\mathrm{T}}$ did not grow in PY medium containing $\mathrm{NaCl}(0-5 \%)$ as the only salt but grew in PY medium supplemented with $0.5-4.0 \%$ sea salts (optimum 1-2\%). Strain ZLD-29 ${ }^{\mathrm{T}}$ grew very weakly in PY medium but grew much better in PY medium supplemented with $0.5-3.0 \% \mathrm{NaCl}$. However, optimum growth of strain ZLD-29 $9^{\mathrm{T}}$ occurred in PY medium supplemented with $1-2 \%$ sea salts. Both strains were unable to grow on TSA (Difco), MacConkey agar (Difco) or BHI agar (Becton Dickinson). With a longer incubation time $(>1$ week), the centres of colonies of strain ZLD-1 $17^{\mathrm{T}}$ developed a brown colour. Strain ZLD-17 differed from strain ZLD- $29^{\mathrm{T}}$ in its ability to hydrolyse tyrosine, ONPG and $p$-nitrophenyl- $\beta$-D-galactopyranoside (PNPG) but not gelatin. Furthermore, strain ZLD-17 ${ }^{\mathrm{T}}$ produced enzymes such as trypsin and $\beta$-galactosidase but strain ZLD-29 $9^{\mathrm{T}}$ did not. The phenotypic characteristics of strains $\mathrm{ZLD}-17^{\mathrm{T}}$ and $\mathrm{ZLD}-29^{\mathrm{T}}$ are summarized in the species description and a comparison of selective characteristics with recognized members of the genus Lysobacter is given in Table 1.

The DNA G $+\mathrm{C}$ content was determined by HPLC according to the method of Mesbah et al. (1989). Respiratory quinones were extracted and determined by HPLC as described by Xie \& Yokota (2003). Polar lipids were extracted and analysed as described by Tindall (1990). For polar lipid analysis, a $6.75 \mathrm{ml}$ portion of chloroform/ methanol $/ 0.3 \%$ aqueous $\mathrm{NaCl}(1: 2: 0.8, \mathrm{v} / \mathrm{v} / \mathrm{v})$ was added to $100 \mathrm{mg}$ freeze-dried cell material. The preparation was stirred overnight and cell debris was pelleted by centrifugation. Polar lipids were recovered into the chloroform phase by adjusting the chloroform $/$ methanol $/ 0.3 \%$ aqueous $\mathrm{NaCl}$ mixture to a ratio of $1: 1: 0.9(\mathrm{v} / \mathrm{v} / \mathrm{v})$ and then dried under nitrogen. The dried polar lipids were resuspended in chloroform/methanol $(2: 1, \mathrm{v} / \mathrm{v})$ and separated by two-dimensional TLC. Total lipid material and specific functional groups were detected using dodecamolybdophosphoric acid (total lipids), Zinzadze reagent (phosphate), ninhydrin (free amino groups), periodate Schiff ( $\alpha$-glycols), Dragendorff reagent (quaternary nitrogen) and anisaldehyde-sulfuric acid (glycolipids). To determine whole-cell fatty acid profiles, strains ZLD$17^{\mathrm{T}}$ and ZLD-29 $9^{\mathrm{T}}$ were grown at $28^{\circ} \mathrm{C}$ for $48 \mathrm{~h}$ on halfstrength $\mathrm{MB}$ agar. Analysis of the fatty acid methyl esters was carried out according to the standard protocol of the Sherlock Microbial Identification System (MIDI, 1999).

The DNA G + C contents of strains ZLD- $17^{\mathrm{T}}$ and ZLD- $29^{\mathrm{T}}$ were 67.9 and $68.2 \mathrm{~mol} \%$, respectively. Both of them had ubiquinone-8 (Q-8) as the major isoprenoid quinone, which is a characteristic feature of members of the genus Lysobacter (Bae et al., 2005). The fatty acid compositions of the novel strains and type strains of recognized Lysobacter species are given in Table 2. The major fatty acids detected (percentages of the total cellular fatty acids) from strains $\mathrm{ZLD}-17^{\mathrm{T}}$ and $\mathrm{ZLD}-29^{\mathrm{T}}$ were summed feature 3 (iso- $\mathrm{C}_{15: 0}$ 2-OH and/or $\mathrm{C}_{16: 1} \omega 7 c ; 21.2$ and $28.4 \%$, respectively), iso- $\mathrm{C}_{17: 1} \omega 9 c(16.0$ and $18.8 \%)$, iso- $\mathrm{C}_{16: 0}$ (14.2 and $\left.7.3 \%\right)$, $\mathrm{C}_{16: 0}(9.3$ and $13.2 \%)$ and iso- $\mathrm{C}_{11: 0} 3-\mathrm{OH}$ (6.8 and $6.1 \%)$. Strains ZLD-17 $7^{\mathrm{T}}$ and ZLD-29 ${ }^{\mathrm{T}}$ also differed from each other in the relative amounts of anteiso- $\mathrm{C}_{15: 0}$. Compared with all recognized members of the genus Lysobacter, both novel strains contained larger amounts of summed feature 3 but significantly smaller amounts of iso- $\mathrm{C}_{15: 0}$. The polar lipid profiles of strains $\mathrm{ZLD}-17^{\mathrm{T}}$ and ZLD-29 $9^{\mathrm{T}}$ (Fig. 2) were similar in terms of their major components, including phosphatidylethanolamine, phosphatidylglycerol and diphosphatidylglycerol, which are characteristic polar lipids of the genus Lysobacter (Park et al., 2008; Romanenko et al., 2008). In addition, both strains contained minor amounts of an unknown aminolipid (AL1) and three unknown phospholipids (PL1-3). Nevertheless, some small differences could be observed in their polar lipid profiles. Strain $\mathrm{ZLD}-17^{\mathrm{T}}$ differed from strain ZLD-29 ${ }^{\mathrm{T}}$ by the presence of unknown phospholipids PL4 and PL5 and the absence of unknown phospholipid PL6. 
Table 1. Phenotypic characteristics of strains ZLD $-17^{\top}$ and ZLD- $29^{\top}$ and type strains of species of the genus $L y s o b a c t e r$

Strains: 1, ZLD-17 ${ }^{\mathrm{T}}$; 2, ZLD-29 ${ }^{\mathrm{T}}$; 3, L. capsici KCTC $22007^{\mathrm{T}}$; 4, L. spongiicola DSM 21749 ${ }^{\mathrm{T}}$; 5, L. koreensis KACC $11581^{\mathrm{T}}$; 6, L. niastensis DSM $18481^{\mathrm{T}}$; 7, L. enzymogenes DSM $2043^{\mathrm{T}} ; 8$, L. niabensis DSM $18244^{\mathrm{T}}$; 9, L. xinjiangensis RCML-52 ${ }^{\mathrm{T}}$ (Liu et al., 2011); 10, L. oryzae YC6269 ${ }^{\mathrm{T}}($ Aslam et al., 2009; Liu et al., 2011); 11, L. yangpyeongensis DSM $17635^{\mathrm{T}}$ (Aslam et al., 2009; Wang et al., 2009); 12, L. ximonensis XM415 ${ }^{\mathrm{T}}$ (Wang et al., 2009); 13, L. antibioticus DSM 2044 ${ }^{\mathrm{T}}$ (Park et al., 2008; Wang et al., 2009); 14, L. brunescens DSM 6979 ${ }^{\mathrm{T}}$ (Ten et al., 2009; Wang et al., 2009); 15, L. concretionis KCTC $12205^{\mathrm{T}}$ (Wang et al., 2009); 16, L. daejeonensis DSM $17634^{\mathrm{T}}$ (Weon et al., 2006; Wang et al., 2009); 17, L. defluvii DSM 18482 ${ }^{\mathrm{T}}$ (Yassin et al., 2007; Wang et al., 2009); 18, L. gummosus DSM 6980 ${ }^{\mathrm{T}}$ (Park et al., 2008; Wang et al., 2009); 19, L. panaciterrae DSM 17927 ${ }^{\mathrm{T}}$ (Ten et al., 2009); 20, L. soli DCY21 ${ }^{\mathrm{T}}$ (Srinivasan et al., 2010); 21, L. dokdonensis DS-58 ${ }^{\mathrm{T}}$ (Oh et al., 2011); 22, L. ruishenii CTN-1 ${ }^{\mathrm{T}}$ (Wang et al., 2011). Data for strains 1-8 are from this study. +, Positive; -, negative; w, weakly positive; ND, no data available.

\begin{tabular}{|c|c|c|c|c|c|c|c|c|c|c|c|c|c|c|c|c|c|c|c|c|c|c|}
\hline Characteristic & 1 & 2 & 3 & 4 & 5 & 6 & 7 & 8 & 9 & 10 & 11 & 12 & 13 & 14 & 15 & 16 & 17 & 18 & 19 & 20 & 21 & 22 \\
\hline Catalase/oxidase & $\mathrm{w} /+$ & $\mathrm{w} /+$ & $+1+$ & $+1+$ & $+1-$ & $+1+$ & $+/+$ & $+/+$ & $+/+$ & $+/+$ & $-1+$ & $+1-$ & $+/+$ & $+/ t$ & $+/+$ & $+/+$ & $+/+$ & $+/+$ & $-1+$ & $+/+$ & $+1+$ & $+/+$ \\
\hline Nitrate reduction & $\mathrm{W}$ & $\mathrm{w}$ & - & - & - & + & - & - & - & - & - & - & + & - & - & + & - & - & - & + & - & + \\
\hline Aesculin hydrolysis & + & + & + & - & - & + & + & - & + & + & - & + & + & + & - & + & - & + & + & $\mathrm{ND}$ & - & + \\
\hline Gelatin hydrolysis & - & + & + & + & + & + & + & + & + & + & + & + & + & + & + & + & + & + & + & $\mathrm{ND}$ & + & + \\
\hline Salinity range $(\%)$ & $0.5-4.0^{*}$ & $+0-3$ & $0-2$ & $0-6$ & $0-2$ & $0-1$ & $0-2$ & $0-1$ & $0-2$ & 0 & $0-1$ & $0-1$ & $0-1$ & $0-1$ & ND & $0-3$ & $0-6$ & $0-2$ & $0-3$ & $\mathrm{ND}$ & $0-0.5$ & $0-1$ \\
\hline \multicolumn{23}{|l|}{ Assimilation of: } \\
\hline D-Glucose & - & - & + & - & - & - & + & - & - & - & - & + & + & - & - & + & - & + & + & + & - & + \\
\hline L-Arabinose & - & - & - & - & + & - & + & - & - & - & - & - & - & - & - & - & - & - & - & - & - & $\mathrm{ND}$ \\
\hline D-Mannose & - & - & + & - & - & - & + & - & - & - & - & + & + & - & - & - & - & + & + & + & - & - \\
\hline D-Mannitol & - & - & - & - & + & - & + & - & - & - & - & - & - & - & - & - & + & - & - & - & - & ND \\
\hline $\mathrm{N}$-Acetylglucosamine & - & - & - & - & - & + & + & - & - & - & - & + & + & - & - & - & - & + & + & + & - & + \\
\hline Maltose & - & - & + & - & - & + & + & - & - & - & - & + & + & - & - & + & + & + & + & + & $\mathrm{W}$ & - \\
\hline Malic acid & - & - & - & - & - & - & + & - & - & - & + & - & + & - & - & - & - & + & + & - & $\mathrm{ND}$ & ND \\
\hline Trisodium citrate & - & - & - & - & + & - & + & - & - & - & - & - & - & - & - & - & - & - & + & - & - & ND \\
\hline \multicolumn{23}{|l|}{ Enzyme activities } \\
\hline Trypsin & + & - & + & - & - & + & + & + & - & + & + & - & - & $\mathrm{ND}$ & $\mathrm{ND}$ & + & $\mathrm{ND}$ & - & $\mathrm{ND}$ & - & - & + \\
\hline$\alpha$-Galactosidase & - & - & + & - & - & - & - & - & - & - & - & - & - & - & - & - & - & - & $\mathrm{ND}$ & - & - & - \\
\hline$\alpha$-Glucosidase & - & - & + & - & - & - & + & + & - & + & + & + & - & + & + & + & + & + & $\mathrm{ND}$ & + & $\mathrm{ND}$ & - \\
\hline $\begin{array}{l}N \text {-Acetyl- } \beta \text { - } \\
\text { glucosaminidase }\end{array}$ & - & - & - & - & - & - & - & + & - & - & + & + & - & - & - & - & - & + & $\mathrm{ND}$ & + & ND & - \\
\hline$\beta$-Glucosidase & - & - & + & - & - & - & + & - & - & - & - & - & + & + & - & - & - & + & $\mathrm{ND}$ & + & ND & - \\
\hline$\beta$-Galactosidase & + & - & - & - & - & + & + & - & - & - & - & + & + & - & - & - & - & + & - & - & - & - \\
\hline
\end{tabular}

${ }^{\star}$ Strain $\mathrm{ZLD}-17^{\mathrm{T}}$ did not grow with $\mathrm{NaCl}$ as the only salt. The value given refers to growth in sea salts.

Therefore, on the basis of the data presented, strains ZLD$17^{\mathrm{T}}$ and ZLD-29 ${ }^{\mathrm{T}}$ represent two novel species of the genus Lysobacter, for which the names Lysobacter korlensis sp. nov. and Lysobacter bugurensis sp. nov. are proposed, respectively.

\section{Description of Lysobacter korlensis sp. nov.}

Lysobacter korlensis (kor.len'sis. N.L. masc. adj. korlensis pertaining to Korla, a city of Xinjiang Province in northwest China, from where the type strain was isolated).

Cells are aerobic, Gram-reaction-negative, gliding and rodshaped $(0.3-0.4 \times 1.0-2.5 \mu \mathrm{m})$. Colonies are yellow, circular, convex and $1-2 \mathrm{~mm}$ in diameter with clear margins after incubation at $28{ }^{\circ} \mathrm{C}$ for 2 days on half-strength $\mathrm{MB}$ agar (Difco). Growth occurs at $10-37{ }^{\circ} \mathrm{C}$ (optimum $28{ }^{\circ} \mathrm{C}$ ), at $\mathrm{pH}$ 6-11 (optimum $\mathrm{pH} 7-8$ ) and in $0.5-4.0 \%(\mathrm{w} / \mathrm{v})$ sea salts (optimum 1.0-2.0\%) but no growth occurs in media containing $\mathrm{NaCl}$ as the only salt. Weakly positive for catalase; oxidase-positive. Exhibits $\alpha$-haemolysis. Hydrolyses aesculin, casein, starch, tyrosine, ONPG and PNPG but not gelatin, adenine, guanine, hypoxanthine, xanthine, elastin, keratin, testosterone, hippurate, CM-cellulose or chitin. Nitrate reduction and acetoin production (Voges-Proskauer reaction) are weakly positive. Hydrogen sulfide production, citrate utilization, indole production and activities of arginine dihydrolase, lysine decarboxylase, ornithine decarboxylase, urease and tryptophan deaminase are negative (API 20 E). Negative for assimilation of D-glucose, L-arabinose, D-mannose, D-mannitol, $N$-acetylglucosamine, maltose, potassium gluconate, capric acid, adipic acid, malic acid, trisodium citrate, phenylacetic acid, L-rhamnose, ribose, sucrose, suberic acid, lactic acid, alanine, glycogen, melibiose, 3-hydroxybutyric acid, proline, inositol, itaconic acid, sodium malonate, sodium acetate, potassium 5-ketogluconate, 3-hydroxybenzoic acid, L-serine, salicin, L-fucose, D-sorbitol, propionic acid, valeric acid, L-histidine, potassium 2-ketogluconate and 4-hydroxybenzoic acid (API $20 \mathrm{NE}$ and API ID 32GN). Acid is produced from D-glucose, but not from D-mannitol, glycerol, maltose, D-arabinose, 
Table 2. Cellular fatty acid compositions (\%) of strains ZLD-17 $7^{\top}$ and ZLD- $29^{\top}$ and type strains species of the genus $L y$ sobacter

Strains: 1, ZLD-17 ${ }^{\mathrm{T}}$; 2, ZLD-29 ${ }^{\mathrm{T}}$; 3, L. capsici KCTC $22007^{\mathrm{T}}$; 4, L. spongiicola DSM 21749 ${ }^{\mathrm{T}}$; 5, L. koreensis KACC 11581 ${ }^{\mathrm{T}}$; 6, L. niastensis DSM $18481^{\mathrm{T}} ; 7$, L. enzymogenes DSM 2043 ${ }^{\mathrm{T}} ; 8$, L. niabensis DSM $18244^{\mathrm{T}} ; 9$, L. xinjiangensis RCML-52 ${ }^{\mathrm{T}}$ (Liu et al., 2011); 10, L. oryzae YC6269 ${ }^{\mathrm{T}}($ Aslam et al., 2009); 11, L. yangpyeongensis DSM $17635^{\mathrm{T}}$ (Weon et al., 2007); 12, L. ximonensis XM415 ${ }^{\mathrm{T}}$ (Wang et al., 2009); 13, L. antibioticus DSM 2044 ${ }^{\mathrm{T}}$ (Weon et al., 2007); 14, L. brunescens DSM 6979 ${ }^{\mathrm{T}}$ (Weon et al., 2007); 15, L. concretionis KCTC $12205^{\mathrm{T}}$ (Weon et al., 2007); 16, L. daejeonensis DSM $17634^{\mathrm{T}}$ (Weon et al., 2007); 17, L. defluvii DSM $18482^{\mathrm{T}}$ (Yassin et al., 2007); 18, L. gummosus DSM 6980 ${ }^{\mathrm{T}}$ (Weon et al., 2007); 19, L. panaciterrae DSM $17927^{\mathrm{T}}$ (Ten et al., 2009); 20, L. soli DCY21 ${ }^{\mathrm{T}}$ (Srinivasan et al., 2010); 21, L. dokdonensis DS-58 ${ }^{\mathrm{T}}$ (Oh et al., 2011); 22, L. ruishenii CTN-1 ${ }^{\mathrm{T}}$ (Wang et al., 2011). Data for strains 1-8 are from this study (cultured on half-strength MB agar at $28{ }^{\circ} \mathrm{C}$ for $48 \mathrm{~h}$ ).,$-<1 \%$ or not detected.

\begin{tabular}{|c|c|c|c|c|c|c|c|c|c|c|c|c|c|c|c|c|c|c|c|c|c|c|}
\hline Fatty acid & 1 & 2 & 3 & 4 & 5 & 6 & 7 & 8 & 9 & 10 & 11 & 12 & 13 & 14 & 15 & 16 & 17 & 18 & 19 & 20 & 21 & 22 \\
\hline $\mathrm{C}_{10: 0} 3-\mathrm{OH}$ & - & - & 1.0 & - & - & - & - & - & - & - & - & - & - & - & - & - & - & - & - & - & - & - \\
\hline iso- $\mathrm{C}_{11: 0} 3-\mathrm{OH}$ & 6.8 & 6.1 & 8.8 & 6.9 & 2.8 & 6.4 & 6.2 & 7.3 & 6.5 & 3.2 & 5.5 & 5.2 & 8.0 & 7.2 & 6.9 & 6.0 & 7.2 & 9.7 & 6.9 & 5.8 & 7.8 & 3.9 \\
\hline iso- $\mathrm{C}_{12: 0}$ & 1.4 & - & - & 1.0 & - & - & - & - & - & - & 1.1 & - & - & - & - & 2.0 & - & - & - & - & - & - \\
\hline $\mathrm{C}_{14: 0}$ & 1.2 & 1.0 & 2.8 & - & - & - & 1.6 & 1.0 & - & 2.8 & - & 1.7 & 1.1 & - & - & - & - & - & - & - & - & - \\
\hline iso- $\mathrm{C}_{15: 0}$ & 5.3 & 3.6 & 30.3 & 16.7 & 20.0 & 42.1 & 35.9 & 15.7 & 19.1 & 12.5 & 14.5 & 22.6 & 24.9 & 19.6 & 33.6 & 13.1 & 40.9 & 25.2 & 29.5 & 34.3 & 18.7 & 21.4 \\
\hline iso- $\mathrm{C}_{15: 1}$ AT 5 & - & - & 1.8 & - & 4.1 & 1.2 & - & 2.0 & - & 3.9 & 3.1 & - & 1.0 & - & - & - & - & 1.7 & - & - & - & - \\
\hline iso- $\mathrm{C}_{15: 1} \mathrm{~F}$ & 1.4 & - & - & - & - & - & - & - & 2.1 & - & - & 1.8 & - & 1.7 & 3.2 & 3.2 & - & - & - & - & - & 4.4 \\
\hline anteiso- $C_{15: 0}$ & 4.6 & - & 1.4 & - & - & - & 1.7 & 1.6 & 1.0 & 2.2 & 5.1 & 6.3 & 3.8 & 2.6 & 1.2 & 3.2 & - & 5.5 & 4.5 & 1.8 & 4.9 & 1.9 \\
\hline$C_{16: 0}$ & 9.3 & 13.2 & 7.6 & 2.7 & 2.9 & 2.5 & 4.6 & 2.3 & 3.5 & 2.7 & 3.1 & 7.0 & 8.0 & 1.5 & 1.5 & 1.4 & 2.9 & 6.0 & 5.2 & 1.4 & 1.9 & 6.8 \\
\hline $\mathrm{C}_{16: 1} \omega 7 c$ alcohol & - & - & - & - & 6.1 & - & - & 4.5 & 1.7 & 3.5 & 8.8 & - & 1.6 & - & - & - & - & 1.7 & - & - & - & - \\
\hline iso- $\mathrm{C}_{17: 0}$ & 2.1 & 3.7 & 4.8 & 3.3 & 10.1 & 5.7 & 2.6 & 7.7 & 3.9 & 12.3 & 1.9 & 1.5 & 3.4 & 2.3 & 4.1 & - & 11.1 & 7.8 & 16.0 & 17.2 & 2.5 & 3.5 \\
\hline iso- $\mathrm{C}_{17: 1} \omega 9 c$ & 16.0 & 18.8 & 6.6 & 18.0 & 20.5 & 14.0 & 5.7 & 17.6 & 16.4 & 21.5 & 6.7 & 6.7 & 6.4 & 15.5 & 15.1 & 6.7 & 5.8 & 12.2 & 23.1 & 19.5 & 14.0 & 15.3 \\
\hline anteiso- $\mathrm{C}_{17: 0}$ & 2.4 & - & - & - & - & - & - & - & - & - & 1.1 & - & - & - & - & - & - & 1.4 & 1.4 & - & 0.6 & - \\
\hline $\mathrm{C}_{18: 1} \omega 7 c$ & 1.9 & 3.2 & 2.1 & - & - & - & 3.0 & - & - & - & - & 1.2 & 1.7 & - & - & - & - & 2.5 & - & 1.1 & - & - \\
\hline Unknown 11.799 & - & - & - & - & - & - & - & - & - & - & - & - & 2.0 & - & - & - & - & 1.8 & 1.4 & - & - & - \\
\hline Summed feature $3^{*}$ & 21.2 & 28.4 & 14.0 & 2.0 & - & 4.7 & 15.9 & 1.0 & 1.7 & 1.1 & 3.3 & 2.9 & 8.3 & 9.5 & - & 6.1 & - & 6.4 & 4.8 & 3.4 & 2.8 & 4.5 \\
\hline
\end{tabular}

${ }^{*}$ Summed feature 3 comprises iso- $\mathrm{C}_{15: 0} 2-\mathrm{OH}$ and/or $\mathrm{C}_{16: 1} \omega 7 \mathrm{c}$.

L-arabinose, D-ribose, D-xylose, D-galactose, D-fructose, D-mannose, L-rhamnose, lactose, sucrose or trehalose. According to the API ZYM gallery (bioMérieux), positive for alkaline phosphatase, esterase (C4), esterase lipase (C8), leucine arylamidase, trypsin, $\alpha$-chymotrypsin, acid phosphatase, naphthol-AS-BI-phosphohydrolase and $\beta$-galactosidase activities but negative for lipase (C14), valine arylamidase, cystine arylamidase, $\alpha$-galactosidase, $\beta$-glucuronidase, $\alpha$-glucosidase, $\beta$-glucosidase, $N$-acetyl- $\beta$-glucosaminidase, $\alpha$-mannosidase and $\alpha$-fucosidase activities. The predominant respiratory quinone is Q-8. The polar lipids consist of diphosphatidylglycerol, phosphatidylglycerol, phosphatidylethanolamine, an unknown aminolipid and five unknown phospholipids. The major fatty acids are summed feature 3 (iso- $\mathrm{C}_{15: 0} 2-\mathrm{OH}$ and/or $\mathrm{C}_{16: 1} \omega 7 c$ ), iso$\mathrm{C}_{17: 1} \omega 9 c$, iso- $\mathrm{C}_{16: 0}, \mathrm{C}_{16: 0}$ and iso- $\mathrm{C}_{11: 0} 3-\mathrm{OH}$; detailed fatty acid compositions are given in Table 2 .

The type strain, ZLD-17 ${ }^{\mathrm{T}}$ (=CCTCC AB $207174^{\mathrm{T}}=\mathrm{KCTC}$ $23076^{\mathrm{T}}$ ), was isolated from an arid soil sample collected from Korla, Xinjiang Province, north-west China. The DNA G $+\mathrm{C}$ content of the type strain is $67.9 \mathrm{~mol} \%$.

\section{Description of Lysobacter bugurensis sp. nov.}

Lysobacter bugurensis (bu.gur.en'sis. N.L. masc. adj. bugurensis pertaining to Bugur, a county of Xinjiang Province in north-west China, from where the type strain was isolated).

Cells are aerobic, Gram-reaction-negative, gliding and rodshaped $(0.6-0.7 \times 1.1-1.5 \mu \mathrm{m})$. Colonies are yellow, circular, convex and $1-2 \mathrm{~mm}$ in diameter with clear margins after incubation at $28{ }^{\circ} \mathrm{C}$ for 2 days on halfstrength $\mathrm{MB}$ agar (Difco). Growth occurs at $10-37{ }^{\circ} \mathrm{C}$ (optimum $28^{\circ} \mathrm{C}$ ), at $\mathrm{pH}$ 6-11 (optimum pH 7-8) and in the presence of $0-3 \%(\mathrm{w} / \mathrm{v}) \mathrm{NaCl}$; optimal growth requires the presence of $1-2 \%(\mathrm{w} / \mathrm{v})$ sea salts. Weakly positive for catalase; oxidase-positive. Exhibits $\alpha$-haemolysis. Hydrolyses aesculin, gelatin, casein and starch but not tyrosine, 


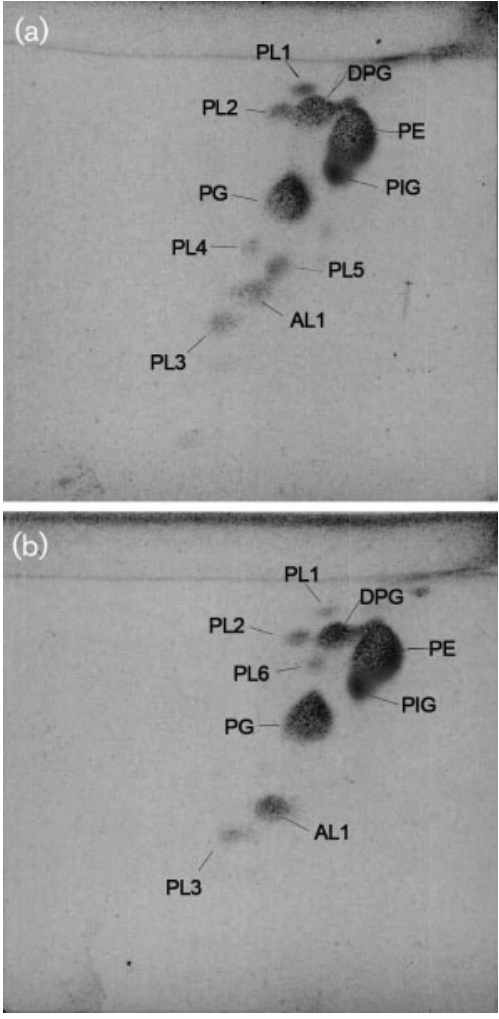

Fig. 2. Two-dimensional TLC of polar lipids of strains ZLD-17 (a) and ZLD-29 $9^{\top}$ (b) stained with $5 \%$ ethanolic molybdophosphoric acid. PE, Phosphatidylethanolamine; PG, phosphatidylglycerol; DPG, diphosphatidylglycerol; AL1, unknown aminolipid; PL1-PL6, unknown phospholipids; PIG, pigment.

ONPG, PNPG, adenine, guanine, hypoxanthine, xanthine, elastin, keratin, testosterone, hippurate, CM-cellulose or chitin. Nitrate reduction is weakly positive. Hydrogen sulfide production, acetoin production (Voges-Proskauer reaction), citrate utilization, indole production and arginine dihydrolase, lysine decarboxylase, ornithine decarboxylase, urease and tryptophan deaminase activities are negative (API $20 \mathrm{E}$ ). Negative for assimilation of D-glucose, L-arabinose, D-mannose, D-mannitol, $N$-acetylglucosamine, maltose, potassium gluconate, capric acid, adipic acid, malic acid, trisodium citrate, phenylacetic acid, L-rhamnose, ribose, sucrose, suberic acid, lactic acid, alanine, glycogen, melibiose, 3-hydroxybutyric acid, proline, inositol, itaconic acid, sodium malonate, sodium acetate, potassium 5-ketogluconate, 3-hydroxybenzoic acid, L-serine, salicin, L-fucose, D-sorbitol, propionic acid, valeric acid, L-histidine, potassium 2-ketogluconate and 4-hydroxybenzoic acid (API $20 \mathrm{NE}$ and API ID 32GN). Acid is produced from D-glucose and maltose but not from D-mannitol, glycerol, D-arabinose, L-arabinose, D-ribose, D-xylose, D-galactose, D-fructose, D-mannose, L-rhamnose, lactose, sucrose or trehalose. According to the API ZYM gallery (bioMérieux), positive for alkaline phosphatase, esterase (C4), esterase lipase (C8), leucine arylamidase, $\alpha$-chymotrypsin, acid phosphatase and
naphthol-AS-BI-phosphohydrolase activities but negative for lipase (C14), valine arylamidase, cystine arylamidase, trypsin, $\alpha$-galactosidase, $\beta$-galactosidase, $\beta$-glucuronidase, $\alpha$-glucosidase, $\beta$-glucosidase, $N$-acetyl- $\beta$-glucosaminidase, $\alpha$-mannosidase and $\alpha$-fucosidase activities. The predominant respiratory quinone is Q-8. The polar lipids consist of diphosphatidylglycerol, phosphatidylglycerol, phosphatidylethanolamine, an unknown aminolipid and four unknown phospholipids. The major fatty acids are summed feature 3 , iso- $\mathrm{C}_{17: 1} \omega 9 c, \mathrm{C}_{16: 0}$, iso- $\mathrm{C}_{16: 0}$ and iso- $\mathrm{C}_{11: 0} 3-\mathrm{OH}$; detailed fatty acid compositions are given in Table 2.

The type strain, ZLD $-29^{\mathrm{T}}$ (=CCTCC AB $207175^{\mathrm{T}}=\mathrm{KCTC}$ $23077^{\mathrm{T}}$ ), was isolated from an arid soil sample collected from Bugur, Xinjiang Province, north-west China. The DNA G $+C$ content of the type strain is $68.2 \mathrm{~mol} \%$.

\section{Acknowledgements}

This work was supported by NWSUAF China (Z111020910) and the R \& D Infrastructure and Facility Development Program from the Ministry of Science and Technology of the People's Republic of China (grant no. 2005DKA21208).

\section{References}

Aslam, Z., Yasir, M., Jeon, C. O. \& Chung, Y. R. (2009). Lysobacter oryzae sp. nov., isolated from the rhizosphere of rice (Oryza sativa L.). Int J Syst Evol Microbiol 59, 675-680.

Bae, H.-S., Im, W.-T. \& Lee, S.-T. (2005). Lysobacter concretionis sp. nov., isolated from anaerobic granules in an upflow anaerobic sludge blanket reactor. Int J Syst Evol Microbiol 55, 1155-1161.

Bowman, J. P. (2000). Description of Cellulophaga algicola sp. nov., isolated from the surfaces of Antarctic algae, and reclassification of Cytophaga uliginosa (ZoBell and Upham 1944) Reichenbach 1989 as Cellulophaga uliginosa comb. nov. Int J Syst Evol Microbiol 50, 1861-1868.

Christensen, P. \& Cook, F. D. (1978). Lysobacter, a new genus of nonfruiting, gliding bacteria with a high base ratio. Int J Syst Bacteriol 28, 367-393.

Chun, J., Lee, J.-H., Jung, Y., Kim, M., Kim, S., Kim, B. K. \& Lim, Y.-W. (2007). EzTaxon: a web-based tool for the identification of prokaryotes based on $16 \mathrm{~S}$ ribosomal RNA gene sequences. Int J Syst Evol Microbiol 57, 2259-2261.

Doetsch, R. N. (1981). Determinative methods of light microscopy. In Manual of Methods for General Bacteriology, pp. 21-33. Edited by P. Gerhardt, R. G. E. Murray, R. N. Costilow, E. W. Nester, W. A. Wood, N. R. Krieg \& G. B. Phillips. Washington, DC: American Society for Microbiology.

Gordon, R. E. \& Smith, M. M. (1955). Proposed group of characters for the separation of Streptomyces and Nocardia. J Bacteriol 69, 147-150.

Kinyon, J. M. \& Harris, D. L. (1979). Treponema innocens, a new species of intestinal bacteria, and emended description of the type strain of Treponema hyodysenteriae Harris et al. Int J Syst Bacteriol 29, 102-109.

Kovács, N. (1956). Identification of Pseudomonas pyocyanea by the oxidase reaction. Nature 178, 703-704.

Lane, D. J. (1991). 16S/23S rRNA sequencing. In Nucleic Acid Techniques in Bacterial Systematics, pp. 115-175. Edited by E. Stackebrandt \& M. Goodfellow. Chichester: Wiley. 
Leifson, E. (1963). Determination of carbohydrate metabolism of marine bacteria. J Bacteriol 85, 1183-1184.

Lin, Y.-C., Uemori, K., de Briel, D. A., Arunpairojana, V. \& Yokota, A. (2004). Zimmermannella helvola gen. nov., sp. nov., Zimmermannella alba sp. nov., Zimmermannella bifida sp. nov., Zimmermannella faecalis sp. nov. and Leucobacter albus sp. nov., novel members of the family Microbacteriaceae. Int J Syst Evol Microbiol 54, 1669-1676.

Liu, M., Liu, Y., Wang, Y., Luo, X., Dai, J. \& Fang, C. (2011). Lysobacter xinjiangensis sp. nov., a moderately thermotolerant and alkalitolerant bacterium isolated from a gamma-irradiated sand soil sample. Int $J$ Syst Evol Microbiol 61, 433-437.

Mesbah, M., Premachandran, U. \& Whitman, W. B. (1989). Precise measurement of the $\mathrm{G}+\mathrm{C}$ content of deoxyribonucleic acid by high-performance liquid chromatography. Int J Syst Bacteriol 39, 159-167.

MIDI (1999). Sherlock Microbial Identification System Operating Manual, version 3.0. Newark, DE: MIDI, Inc.

Oh, K. H., Kang, S. J., Jung, Y. T., Oh, T. K. \& Yoon, J. H. (2011). Lysobacter dokdonensis sp. nov., isolated from soil. Int J Syst Evol Microbiol 61, 1089-1093.

Park, J. H., Kim, R., Aslam, Z., Jeon, C. O. \& Chung, Y. R. (2008). Lysobacter capsici sp. nov., with antimicrobial activity, isolated from the rhizosphere of pepper, and emended description of the genus Lysobacter. Int J Syst Evol Microbiol 58, 387-392.

Romanenko, L. A., Uchino, M., Tanaka, N., Frolova, G. M. \& Mikhailov, V. V. (2008). Lysobacter spongiicola sp. nov., isolated from a deep-sea sponge. Int J Syst Evol Microbiol 58, 370-374.

Smibert, R. M. \& Krieg, N. R. (1994). Phenotypic characterization. In Methods for General and Molecular Bacteriology, pp. 607-654. Edited by P. Gerhardt, R. G. E. Murray, W. A. Woods \& N. R. Krieg. Washington, DC: American Society for Microbiology.

Srinivasan, S., Kim, M. K., Sathiyaraj, G., Kim, H.-B., Kim, Y.-J. \& Yang, D.-C. (2010). Lysobacter soli sp. nov., isolated from soil of a ginseng field. Int J Syst Evol Microbiol 60, 1543-1547.

Stackebrandt, E. \& Goebel, B. M. (1994). Taxonomic note: a place for DNA-DNA reassociation and 16S rRNA sequence analysis in the present species definition in bacteriology. Int $J$ Syst Bacteriol 44, 846-849.

Tamura, K., Dudley, J., Nei, M. \& Kumar, S. (2007). MEGA4: molecular evolutionary genetics analysis (MEGA) software version 4.0. Mol Biol Evol 24, 1596-1599.

Ten, L. N., Jung, H.-M., Im, W.-T., Yoo, S.-A., Oh, H.-M. \& Lee, S.-T. (2009). Lysobacter panaciterrae sp. nov., isolated from soil of a ginseng field. Int J Syst Evol Microbiol 59, 958-963.

Thompson, J. D., Gibson, T. J., Plewniak, F., Jeanmougin, F. \& Higgins, D. G. (1997). The CLUSTAL_X windows interface: flexible strategies for multiple sequence alignment aided by quality analysis tools. Nucleic Acids Res 25, 4876-4882.

Tindall, B. J. (1990). A comparative study of the lipid composition of Halobacterium saccharovorum from various sources. Syst Appl Microbiol 13, 128-130.

Wang, Y., Dai, J., Zhang, L., Luo, X., Li, Y., Chen, G., Tang, Y., Meng, Y. \& Fang, C. (2009). Lysobacter ximonensis sp. nov., isolated from soil. Int J Syst Evol Microbiol 59, 786-789.

Wang, G. L., Wang, L., Chen, H. H., Shen, B., Li, S. P. \& Jiang, J. D. (2011). Lysobacter ruishenii sp. nov., a chlorothalonil-degrading bacterium isolated from a long-term chlorothalonil-contaminated soil. Int J Syst Evol Microbiol 61, 674-679.

Weon, H.-Y., Kim, B.-Y., Baek, Y.-K., Yoo, S.-H., Kwon, S.-W., Stackebrandt, E. \& Go, S.-J. (2006). Two novel species, Lysobacter daejeonensis sp. nov. and Lysobacter yangpyeongensis sp. nov., isolated from Korean greenhouse soils. Int J Syst Evol Microbiol 56, 947-951.

Weon, H.-Y., Kim, B.-Y., Kim, M.-K., Yoo, S.-H., Kwon, S.-W., Go, S.-J. \& Stackebrandt, E. (2007). Lysobacter niabensis sp. nov. and Lysobacter niastensis sp. nov., isolated from greenhouse soils in Korea. Int J Syst Evol Microbiol 57, 548-551.

Xie, C. H. \& Yokota, A. (2003). Phylogenetic analyses of Lampropedia hyalina based on the 16S rRNA gene sequence. J Gen Appl Microbiol 49, 345-349.

Yassin, A. F., Chen, W. M., Hupfer, H., Siering, C., Kroppenstedt, R. M., Arun, A. B., Lai, W. A., Shen, F. T., Rekha, P. D. \& Young, C. C. (2007). Lysobacter defluvii sp. nov., isolated from municipal solid waste. Int J Syst Evol Microbiol 57, 1131-1136. 